\title{
DESENVOLVIMENTO DE METODOLOGIA PARA DETERMINAÇÃO DE 4-CLOROANILINA EM FRANGOS POR CROMATOGRAFIA GASOSA - ESPECTROMETRIA DE MASSAS. ANÁLISE EM TECIDOS TRATADOS COM DIGLUCONATO DE CLORHEXIDINA APÓS O PROCESSAMENTO TÉRMICO ${ }^{1}$
}

\author{
Eduardo VICENTE², Maria Cecília de Figueiredo TOLEDO ${ }^{3, *}$
}

\begin{abstract}
RESUMO
A degradação do antimicrobiano digluconato de clorhexidina (DGCH) durante armazenamento ou processamento térmico pode formar a 4-cloroanilina (CA), um composto potencialmente carcinogênico. Conseqüentemente, o uso deste sanitizante para descontaminação de carcaças de frangos representa uma fonte de risco para o consumidor, devendo ser avaliada a presença da CA no produto tratado. Um método foi desenvolvido para determinação de resíduos de CA em tecidos de frangos. Após a extração com diclorometano, foi feita a limpeza do extrato em cartucho $\mathrm{C}_{18}$ e quantificação por cromatografia gasosa-espectrometria de massas (CG-EM), sem derivação. A recuperação média $(89,2 \%$ - CV 9,9\%.) e o limite de detecção $(1,8 \mathrm{ng} / \mathrm{g})$ foram considerados satisfatórios para os propósitos do estudo. Em amostras tratadas com DGCH e não submetidas a processamento térmico, a quantidade de CA detectada foi relativamente baixa, e provavelmente se originou da solução de tratamento. A fritura e a cocção em forno convencional resultaram em níveis elevados de CA, enquanto que a cocção em panela de pressão não alterou os níveis de CA presentes na amostra crua. Em vista destes resultados e, considerando-se o potencial tóxico da CA, recomenda-se que estes dados sejam levados em consideração quando avaliada a utilização de DGCH como sanitizante de carcaças em abatedouros de aves.

Palavras-chave: 4-cloroanilina*; digluconato de clorhexidina; cromatografia de gás; espectrometria de massas; frango; aminas aromáticas.
\end{abstract}

\section{SUMMARY}

METHODOLOGY FOR 4-CHLOROANILINE DETERMINATION IN POULTRY BY GC-MS. ANALISYS IN CHLORHEXIDINE DIGLUCONATE TREATED TISSUES AFTER TERMICAL PROCESSING. The degradation of the antimicrobial agent chlorhexidine digluconate (CHDG) during storage or thermal process originates 4-chloroaniline (CA), a compound which is potentially carcinogenic. As the use of this sanitizing agent to decontaminate poultry carcasses in processing plants may represent a risk to the consumers, it is important to search for the presence of CA residues in the treated products. A method was developed to quantify CA in poultry tissues. After dichloromethane extraction, the extract was cleaned on a $\mathrm{C}_{18}$ cartridge and the quantitation was performed, without derivatization, by gas chromatography-mass spectrometry (GC-MS). The mean recovery $(89.2 \%-\mathrm{CV} 9.9 \%)$ and detection limit $(1.8 \mathrm{ng} / \mathrm{g})$, were satisfactory for the purposes of the study. Analysis of samples treated with CHDG, before thermal processing, resulted in low CA levels, which probably originated from the treating solution. Frying and cooking in conventional oven resulted in relatively higher levels of CA, while cooking under pressure did not change the residual levels when compared to the raw samples. In view of these results and taking into consideration the toxic potential of CA, the data generated by this study should be considered in the case of use of chlorhexidine as poultry carcasses sanitizing agent.

Keywords: 4-chloroaniline*; gas chcromatography; mass spectrometry; chlorhexidine digluconate; poultry; aromatic amines

\section{1 - INTRODUÇÃO}

A clorhexidina, uma bis-guanida com propriedades bactericida, bacteriostática [6] e fungicida [32], tem sido amplamente utilizada em colutórios, soluções para lentes de contato e pomadas para queimaduras [1, 29]. Nas indústrias que manipulam produtos de origem animal ela tem sido empregada como desinfetante de mãos, equipamentos e superficies $[11,14]$. As evidências da baixa toxicidade, aliadas à eficiência antimicrobiana, levaram ao desenvolvimento de estudos para avaliar a aplicação do digluconato de clorhexidina (DGCH) no controle de microrganismos em carcaças de frango [25, 33]. Entretanto, apesar do benefício tecnológico conse-

1. Recebido para publicação em 29/11/2001. Aceito para publicação em 05/06/2003 (000784).

${ }^{2}$ Centro de Quimica, Instituto de Tecnologia de Alimentos - ITAL. Av Brasil, 2880 - Campinas-SP CEP 13073-001 Fone (OXX19)3743-1771. E-mailevicente@ital.org.br

${ }^{3}$ Departamento de Ciência de Alimentos - Faculdade de Engenharia de Alimentos-FEA - UNICAMP. Cidade Universitária Campus Zeferino Vaz CEP 13001-970. Fone: (19) 3289-2168 Fax 3788-7890 E-mail macecil@fea.unicamp.br

* A quem a correspondência deve ser enviada guido, não é conhecido o comportamento deste antimicrobiano durante o armazenamento e processamento de carcaças tratadas.

Os dados existentes restringem-se à estabilidade do DGCH em medicamentos e soluções comerciais. DOUB et al. [12] desenvolveram metodologia para analisar produtos resultantes da degradação do DGCH em solução a $20 \%$ armazenada por 2,5 a 3 anos no escuro e em temperatura ambiente $\left(20-25^{\circ} \mathrm{C}\right)$. O método foi eficiente na quantificação de 9 dos 11 compostos previamente identificados, entre os quais a 4-cloroanilina (CA), 4-clorofenilguanidina e a 4-clorofeniluréia. A decomposição da DGCH pode ocorrer em função da luz e, principalmente, da temperatura [23]. JAMINET et al. [19] constataram que o $\mathrm{pH}$ influencia esta degradação, tendo observado uma maior formação de CA em soluções autoclavadas a $130^{\circ} \mathrm{C} / 30 \mathrm{~min}$ em $\mathrm{pH} 9$ do que em $\mathrm{pH}$ 6,0.

A aplicação de DGCH em alimentos desperta uma preocupação adicional, já que as aminas aromáticas e seus derivados substituídos, como a 4-cloroanilina, são tóxicos, além de existirem suspeitas de carcinogenicidade e mutagenicidade [21]. Esta suspeita decorre da 
possibilidade de conversão destas aminas, na presença de hemoglobina, em compostos do tipo N-nitroso [17, 26]. Evidências de estudos toxicológicos indicam a toxicidade, imunotoxicidade e carcinogenicidade da CA 3, 4, 20]. O Programa Nacional de Toxicologia da Agência de Proteção Ambiental (EPA) dos Estados Unidos [34] classificou a CA como mutagênica e como provável carcinógeno humano - grupo B2. O Q ${ }_{1}$ determinado (unidade de risco estimado), baseado em taxa de sarcomas de baço em ratos machos, foi de $6,38 \times 10^{-2} \mathrm{mg} / \mathrm{kg} / \mathrm{dia}$ em equivalentes humanos.

Em vista do potencial carcinogênico da CA, ela tem sido monitorada em sangue e urina de pacientes tratados com medicamentos à base de DGCH [2]. Os derivados de anilina também são compostos ligados à atividade industrial, como intermediários na produção de borrachas, plásticos, espuma de poliuretano, pigmentos e produtos farmacêuticos [9]. A CA foi identificada como produto de degradação de pesticidas dos grupos fenil uréia e fenil carbamatos [21]. Devido a sua importância toxicológica, a CA e outras aminas substituídas foram incluidas pela Comunidade Européia na lista de poluentes industriais que devem ser monitorados em águas ambientais [5]. A Legislação Norte Americana estabeleceu tolerâncias para diflubenzuron e seus metabólitos 4-clorofeniluréia e CA em $\operatorname{arroz}(0,02 \mu \mathrm{g} / \mathrm{g})$ e arroz em casca $(0,8 \mu \mathrm{g} / \mathrm{g})$ [35].

Métodos analiticos para a determinação de CA em água utilizaram cromatografia liquida de alta eficiência (CLAE), após uma ou mais etapas de pré-concentração em coluna [5, 9, 10, 30]. A microextração em fase sólida e quantificação por cromatografia gasosa (CG)- espectrometria de massas (EM) ou detector de ionização de chama (DIC) também foram empregadas para análises em água [26] e fluidos biológicos [8]. Foram descritas análises por CLAE -UV ou detector de arranjo de diodos (DAD) $[15,28]$ e por GC-DIC [16] para determinação da $\mathrm{CA}$ em produtos cirúrgicos e desinfetantes formulados com DGCH ou triclocarban. Métodos de análise de CA por CLAE-DAD ou detector eletroquímico foram desenvolvidos em amostras de origem vegetal [31] e mel [7]. No Pesticide Analytical Manual 2000 do FDA - EUA [13], foram descritos métodos para determinação de diflubenzuron e os produtos de degradação 4-feniluréia e CA em amostras de origem vegetal e animal, empregando GC- detector de captura de elétrons (DCE) com derivação ou CLAE-UV.

Tendo em vista a possibilidade de utilização da DGCH para o tratamento de carcaças de frango em abatedouros, torna-se importante, do ponto de vista toxicológico, a determinação de resíduos de CA nas aves tratadas. Considerando que a velocidade de degradação da DGCH e conseqüente formação da CA são dependentes da temperatura e $\mathrm{pH}$, é evidenciada a necessidade do controle de resíduos antes e após o processamento térmico do alimento. Estudos anteriores evidenciaram que após o tratamento de carcaças de aves com DGCH a maior concentração do sanitizante foi encontrada na pele [36]. Uma vez que estes tecidos são direta e intensamente afetados pelo processamento térmico, optou-se por desenvolver um método para análise de CA em frangos e in- vestigar sua presença na pele tratada com $\mathrm{DGCH}$, antes e após tratamentos térmicos convencionais.

\section{2 - MATERIAL E MÉTODOS}

\section{1 - Reagentes}

Os reagentes empregados na etapa de extração foram o diclorometano e sulfato de sódio anidro (PR Mallinckodt). Na limpeza do extrato foram utilizados ácido clorídrico P.A (Merck), hidróxido de sódio P.A. (Merck) e água desmineralizada em sistema Milli Q (Millipore), além dos solventes hexano, acetonitrila e metanol, todos grau residuos de pesticidas (Mallinckodt). Também foram empregados cartuchos de extração em fase sólida (SPE) 3mL C ${ }_{18} 500 \mathrm{mg}$ (JT Baker) e uma solução comercial 20\% de digluconato de clorhexidina (Laboratório Enila) para o tratamento das amostras. A 4cloroanilina 98\% (Aldrich) foi utilizada como padrão para quantificação na cromatografia.

\section{2 - Instrumentação}

O equipamento utilizado foi um cromatógrafo gasoso (HP 6890), equipado com amostrador automático (HP 7683) e espectrômetro de massas (HP 5973), operando com energia de ionização de $70 \mathrm{eV}$ em modo ín seletivo (SIM). As temperaturas foram fixadas em $230^{\circ} \mathrm{C}$ para a fonte de íns e $150^{\circ} \mathrm{C}$ no quadrupolo. A coluna empregada para as análises foi a HP5-MS, 30m x $0,25 \mathrm{~mm}$ di e filme de $0,25 \mu$ e o gás de arraste foi o $\mathrm{He}$, com vazão constante de $1,0 \mathrm{~mL} / \mathrm{min}$. As injeções foram feitas no injetor de temperatura programável (PTV), com "liner" silanizado "open baffled" em modo "splitless". As programações do injetor e da coluna são apresentadas no esquema abaixo:
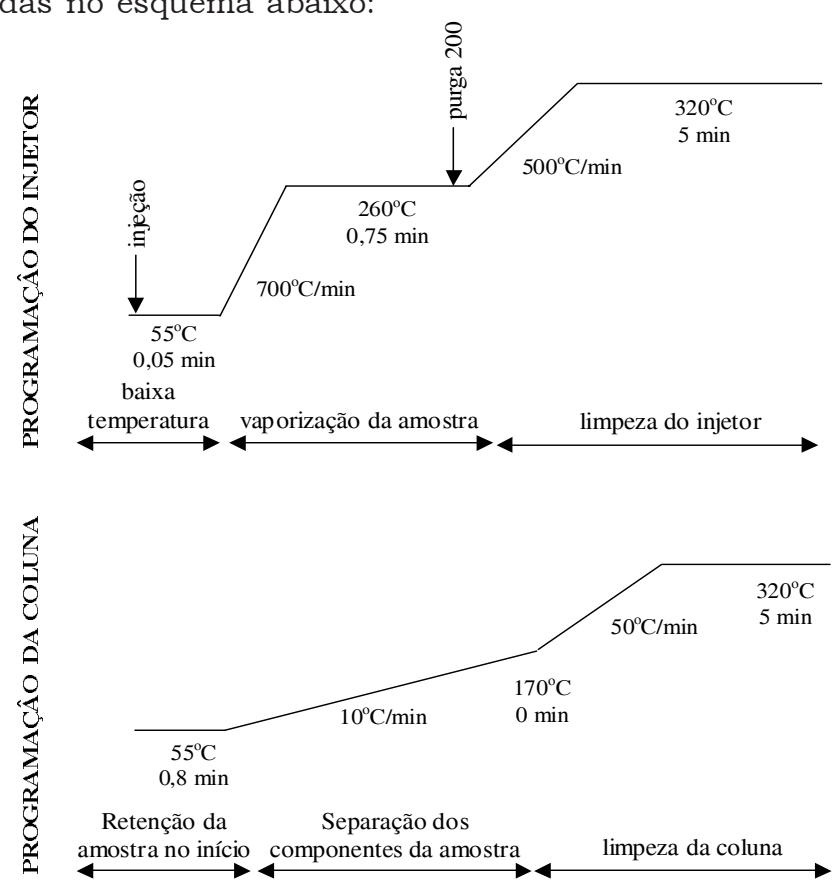

O volume injetado foi de $1 \mu \mathrm{L}$ e a temperatura da interface com o detector de massas foi mantida em $300^{\circ} \mathrm{C}$. 


\section{3 - Preparo das amostras}

\subsection{1 - Tratamento com digluconato de clorhexidina}

Doze cortes de peito com pele, com peso médio de $886 \mathrm{~g}( \pm 54 \mathrm{~g})$, foram imersos por 1 a 2 segundos em uma solução aquosa de $\mathrm{DGCH}$ a $0,4 \mathrm{~g} / \mathrm{L}$, permanecendo em caixas plásticas perfuradas para a remoção do excesso de solução.

\subsection{2 - Processamento térmico de cortes de pei- to tratados}

Amostras formadas por três unidades cada foram submetidas aos seguintes processamentos térmicos convencionais: cocção em panela de pressão/1h, cocção em forno doméstico a gás $1,5 \mathrm{~h}$ (temperatura indicada no forno $200^{\circ} \mathrm{C}$ ) e fritura em óleo de girassol/15 min. (temperatura medida no óleo $180^{\circ} \mathrm{C}$ ). Após o processamento térmico somente as peles foram separadas e homogeneizadas. Também foram separadas as peles de uma amostra tratada, que não foi submetida a processamento térmico a fim de constatar a presença de CA oriunda da solução de tratamento.

\subsection{3 - Processamento de porções definidas de pele tratada em forno de microondas e autoclave}

Após a homogeneização da amostra de pele tratada e não submetida a processamento térmico descrito no item 2.3, foram transferidas seis porções de $10 \mathrm{~g}$ para erlemeyers de $250 \mathrm{~mL}$. Três erlemeyers foram submetidos à autoclavagem, à $120^{\circ} \mathrm{C} / 1 \mathrm{~atm} / 30 \mathrm{~min}$ e outros três à cocção em forno de microondas doméstico de $700 \mathrm{~W}$ (50\% da potência), durante 10 minutos. A CA foi analisada, pelo método desenvolvido, após o processamento térmico. Paralelamente, amostras controle, não tratadas com DGCH, foram submetidas aos mesmos processamentos térmicos estudados, para verificar a existência de outras fontes de CA na matriz.

\section{4 - Método analítico}

Foram pesados $10 \mathrm{~g}$ de amostra, previamente homogeneizada, em um erlenmeyer de $250 \mathrm{~mL}$ com tampa de polietileno. Adicionaram-se $100 \mathrm{~mL}$ de diclorometano e $20 \mathrm{~g}$ de sulfato de sódio anidro, permanecendo a mistura em agitador orbital 300 ciclos $/ \mathrm{min}$ durante $30 \mathrm{~min}$. O extrato foi filtrado em papel de filtro Whatmann 31 com auxilio de um funil de Büchner. A seguir, o diclorometano foi totalmente evaporado em evaporador rotativo $\left(40^{\circ} \mathrm{C}\right)$, até cerca de $1 \mathrm{~mL}$ de resíduo oleoso, evitando-se que a amostra secasse completamente. O resíduo foi dissolvido em $50 \mathrm{~mL}$ de hexano e transferido para um funil de separação de $125 \mathrm{~mL}$. O balão de evaporação foi novamente lavado com $15 \mathrm{~mL}$ de ácido clorídrico $0,1 \mathrm{~N}$, e a solução transferida para $\mathrm{o}$ mesmo funil. Efetuou-se a partição, com agitação moderada por $1 \mathrm{~min}$., sendo a fase inferior (ácido) recolhida em um becker de $150 \mathrm{~mL}$. Este procedimento foi repetido com outras 2 porções de $15 \mathrm{~mL}$ de ácido clorídrico $0,1 \mathrm{~N}$ e as fases ácidas reunidas no mesmo becker.
Foram adicionados cerca de $4 \mathrm{~mL}$ de hidróxido de sódio $1 \mathrm{~N}$ ao extrato ácido e o $\mathrm{pH}$ ajustado para 10 . Um cartucho de $\mathrm{C}_{18}$ (SPE) foi condicionado com $5 \mathrm{~mL}$ de acetonitrila e $10 \mathrm{~mL}$ de água destilada. A amostra já alcalinizada foi percolada pelo cartucho (aproximadamente 0,1 mL/ segundo), que em seguida foi lavado com $20 \mathrm{~mL}$ de água. Posteriormente, a água remanescente entre as particulas do suporte sólido foi completamente eliminada com o auxílio de fluxo de ar comprimido. Todo o eluato aquoso foi descartado e a CA eluída com $5 \mathrm{~mL}$ de acetonitrila, recolhidos em um balão volumétrico de $5 \mathrm{~mL}$. Após o ajuste do volume final com acetonitrila, uma aliquota de $1 \mu \mathrm{L}$ foi injetada em cromatógrafo gasoso acoplado ao espectrômetro de massas (CG-EM).

\section{5 - Limites de detecção, precisão e quantificação por CG-EM}

O limite de detecção do método (LDM) foi determinado pela análise de 8 repetições com amostras fortificadas com $10,7 \mathrm{ng} / \mathrm{g}$ de CA. O desvio-padrão da média dos resultados foi multiplicado pelo valor de $t$ de Student para uma confiabilidade de $99 \%$ e 7 graus de liberdade, de acordo com procedimento descrito por DE BRUIN et al. [8]. Para 8 replicatas e sete graus de liberdade o valor de $t$ de Student é de 2,998. Os resultados destas mesmas 8 determinações foram utilizados para o estabelecimento do limite de quantificação do método (LQM), com base em KEITH et al. [22] e LONG \& WINEFORDNER [24], que o definem como 10 vezes o valor do desvio padrão. A precisão do método foi calculada pelo coeficiente de variação $(\mathrm{CV})$, calculado a partir das determinações de amostras fortificadas em 6 diferentes niveis $(10,7 ; 53,5 ; 107,0 ; 214,0 ; 535,0$ e $4280 \mathrm{ng} / \mathrm{g}$ ), com cinco repetições em cada nivel. A quantificação foi feita por curva de calibração externa.

\section{6 - Robustez do método}

O comportamento do método frente a pequenas modificações nas condições de trabalho foi testado de acordo com o procedimento descrito por YOUDEN [37]. Neste teste foram avaliadas sete variáveis combinadas em 8 determinações, efetuadas em amostras de pele fortificadas com 200ng/g de CA. As condições alternativas avaliadas foram: duas de partições com ácido clorídrico $0,1 \mathrm{~N}$; evaporação parcial do diclorometano; $\mathrm{pH}=7$ no extrato aquoso percolado pelo cartucho de $\mathrm{C}_{18}$; eliminação da etapa de lavagem do cartucho de $\mathrm{C}_{18}$ com água; eluição da CA com $4 \mathrm{~mL}$ de acetonitrila e utilização de cartucho de $\mathrm{C}_{18}$ recondicionado.

\section{7 - Confirmação de identidade}

Para a confirmação da identidade da CA, os extratos foram injetados nas mesmas condições cromatográficas, porém com o detector de massas programado para o modo de varredura, denominado SCAN (70eV). Foram comparados os espectros dos picos obtidos a partir de amostras tratadas, amostras fortificadas e padrões analiticos. Adicionalmente, avaliou-se a coincidência com os espectros da biblioteca NIST 98. 


\section{3 - RESULTADOS E DISCUSSÃO}

\section{1 - Método analítico}

Entre os solventes testados, o diclorometano foi o que possibilitou uma extração eficiente do analito, permitindo a solubilização adequada da matriz, com maior facilidade para evaporação. Outros solventes avaliados, como a acetonitrila e o metanol, permitiram a extração, mas dificultaram a evaporação devido às pressões de vapor elevadas e miscibilidade com a água. As recuperações foram baixas utilizando-se estes solventes, provavelmente devido à perdas por volatilização.

Outro aspecto positivo alcançado pela extração com o diclorometano foi a exclusão da possibilidade de extração da clorhexidina presente na matriz. Em meio aquoso a clorhexidina encontra-se na forma ionizada, com pouca afinidade por solventes orgânicos. A eliminação dos componentes lipídicos da matriz foi conseguida com a partição com solvente orgânico em meio ácido, pois a CA protonada (Figura 1) permaneceu solúvel no meio aquoso enquanto os componentes menos polares foram eliminados com o solvente.
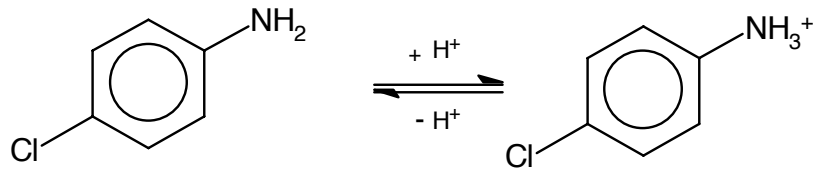

FIGURA 1. Protonação reversivel da 4-cloroanilina em meio ácido

O diclorometano e o hexano foram os solventes avaliados para esta partição. A densidade elevada do diclorometano tornou necessário o uso de vidraria adicional para a separação das fases, além de propiciar a formação de emulsão. Já o hexano não apresentou estes inconvenientes, permitindo a remoção eficiente dos coextrativos. A estrutura neutra da molécula foi restabelecida com a alcalinização do extrato aquoso, permitindo a retenção da CA no $\mathrm{C}_{18}$. Considerando o $\mathrm{pK}_{\mathrm{a}} 4,15$ determinado para a CA [5], em pH próximo de 7, a molécula deveria estar em sua forma neutra . Entretanto, foi constatado que as recuperações neste $\mathrm{pH}$ eram um pouco menores que em $\mathrm{pH}$ alcalino, o que pode ser atribuído à presença de resíduos ácidos no suporte do $\mathrm{C}_{18}$, permitindo a eluição precoce da CA. Notou-se, ainda, que quando a eluição era feita imediatamente após a passagem da solução alcalina, a acetonitrila apresentava turbidez. Este problema foi solucionado pela lavagem da coluna com $20 \mathrm{~mL}$ de água destilada, para eliminar o excesso de hidróxido de sódio e outros possiveis compostos polares introduzidos juntamente com a amostra. A eluição do analito com $5 \mathrm{~mL}$ de acetonitrila proporcionou uma boa recuperação e sensibilidade, sem a necessidade de evaporação da amostra. Caso a evaporação da acetonitrila venha a ser feita para melhorar a sensibilidade, devem ser tomadas precauções para evitar a volatilização da CA. O aumento da massa inicial de amostra também é uma alternativa para aumentar a sensibilidade do método.

\section{2 - Validação do método}

O limite de detecção do método foi calculado em $1,8 \mathrm{ng} / \mathrm{g}$ e o limite para a quantificação foi 8,0ng/g. Em concentrações inferiores ao LQM foi possivel detectar os picos, mas a razão entre o ín alvo (127) e o qualificador (129) ficava fora da tolerância relativa de $20 \%$, comprometendo a confiabilidade da quantificação. A sensibilidade do método proposto pode ser aumentada, se necessário, pela introdução da derivação e pela concentração do extrato final. Entretanto, serão necessários estudos adicionais para estabelecer estes procedimentos. A recuperação média das determinações em amostras fortificadas (Tabela 1) foi de 89,2\% e o CV foi 9,94\%.

TABELA 1. Recuperação da 4-cloroanilina em pele fortificada com diferentes concentrações.

\begin{tabular}{|c|c|c|}
\hline \multirow{2}{*}{$\begin{array}{l}\text { Nível de Fortificação } \\
\qquad(\mathrm{ng} / \mathrm{g})\end{array}$} & \multicolumn{2}{|c|}{ 4-cloroanilina ${ }^{1}$} \\
\hline & Recuperação média (\%) & $\mathrm{CV}(\%)^{2}$ \\
\hline 10,7 & $103 \pm 4$ & 3,6 \\
\hline 53,5 & $89 \pm 7$ & 8,3 \\
\hline 107,0 & $91 \pm 6$ & 6,1 \\
\hline 214,0 & $89 \pm 5$ & 6,0 \\
\hline 535,0 & $83 \pm 3$ & 3,8 \\
\hline 4280,0 & $80 \pm 4$ & 5,0 \\
\hline
\end{tabular}

A análise de variância e o teste de Tukey permitiram constatar que houve diferença significativa entre as recuperações de $10,7 \mathrm{ng} / \mathrm{g}$ e $21,4 \mathrm{ng} / \mathrm{g}$, ao nivel de erro de 5\%. Entretanto, não houve diferença estatistica entre os demais niveis de fortificação. Foi constatado que a recuperação nas amostras fortificadas com $10,7 \mathrm{ng} / \mathrm{g}$ foi maior do que nos demais niveis. Não houve diferença significativa entre as repetições dentro de cada um dos seis niveis de fortificação, sendo o $\mathrm{CV}$ inferior a $10 \%$, o que indica que a repetibilidade do método foi satisfatória. Estes resultados estão em concordância com os critérios publicados por HORWITZ [18], considerando aceitável um CV de até 20\% em determinações onde a concentração dos analitos esteja na faixa de $\mathrm{ng} / \mathrm{g}$ (ppb).

O teste de robustez mostrou que a recuperação da CA sofreu influência, em ordem decrescente de importância, do $\mathrm{pH}$ do extrato aquoso, da evaporação do diclorometano, do número de partições com ácido clorídrico $0,1 \mathrm{~N}$, do volume da acetonitrila empregado para a eluição do analito, da lavagem do cartucho de $\mathrm{C}_{18} \mathrm{com}$ água, da utilização de cartucho de $\mathrm{C}_{18}$ novo e da utilização do sulfato de sódio anidro na extração. Estes resultados indicaram que as condições estabelecidas no procedimento analítico precisam ser seguidas, mas existe uma margem de segurança no volume da acetonitrila definido e a reutilização do cartucho de $\mathrm{C}_{18}$ pode ser adotada para redução do custo da análise. 
3.3 - Análise de 4-cloroanilina em amostras tratadas com digluconato de clorhexidina

\subsection{1 - Em cortes de peito preparados por pro- cessamentos térmicos convencionais}

Foi possivel detectar residuos de CA na pele dos cortes de peito tratadas com DGCH, sendo que os residuos foram maiores nas amostras submetidas a fritura e cocção em forno a gás (Tabela 2).

TABELA 2. Resíduos de 4-cloroanilina em amostras de pele tratadas com digluconato de clorhexidina, antes e após o processamento térmico.

\begin{tabular}{lcc}
\hline \multicolumn{1}{c}{ Tipo de processamento } & \multicolumn{2}{c}{ 4-Cloroanilina $(\mathrm{ng} / \mathrm{g})$} \\
\cline { 2 - 3 } & Média $^{1}$ & $\mathrm{CV}(\%)^{2}$ \\
\hline Não processada termicamente & $20 \pm 2$ & 9,6 \\
$\begin{array}{l}\text { Coç̧ão em forno a gás } \\
\text { convencional } 200^{\circ} \mathrm{C} / 2 \mathrm{~h}\end{array}$ & $133 \pm 14$ & 10,2 \\
$\begin{array}{l}\text { Cozimento em panela de } \\
\text { pressão/ 1h }\end{array}$ & $19 \pm 1$ & 4,6 \\
$\begin{array}{l}\text { Fritura em óleo de girassol } \\
180^{\circ} \mathrm{C} / 15 \text { min. }\end{array}$ & $1628 \pm 108$ & 6,6 \\
\hline
\end{tabular}

${ }^{1}$ Análises com 3 repetições

${ }_{2}^{2} \mathrm{CV}(\%)$ - Coeficiente de variação \%

Os niveis determinados em amostras cozidas em panela de pressão não diferiram estatisticamente daqueles obtidos em amostra não processada termicamente. Em amostras assadas (cocção em forno a gás convencional) e fritas os niveis foram bem maiores, provavelmente em virtude das temperaturas mais elevadas às quais a pele foi submetida. Em vista da CA possuir propriedades físico-quimicas que favorecem sua volatilização quando aquecida, deve ser considerado que parte da $\mathrm{CA}$, gerada pela degradação do $\mathrm{DGCH}$, pode ter sido eliminada durante o processamento térmico. Este fato significa que a quantidade de CA formada pode ter sido maior que a encontrada nas análises efetuadas. Este raciocinio está de acordo com o observado por NAGAYAMA \& KIKUGAWA [27], onde a 2-cloroanilina, formada a partir da degradação do agrotóxico clorprophan, foi reduzida durante a cocção e fritura de batatas contaminadas. $\mathrm{Na}$ amostra cozida em panela de pressão, deve ainda ser considerada a solubilização da CA, já que a amostra ficou em contato direto com a água aquecida. Nas amostras controle, sem tratamento com o DGCH, não foi encontrada CA antes ou após os diferentes processamentos térmicos, descartando-se assim a possibilidade de formação de CA a partir de componentes da matriz.

Pequenas quantidades de CA foram encontradas em amostras tratadas mas não submetidas a processamento térmico. A origem destes resíduos foi, provavelmente, a solução de DGCH utilizada para o tratamento. Em análise feita pelo fabricante do DGCH $20 \%$, utilizado no presente estudo, foram determinados $78,7 \mathrm{mg} / \mathrm{L}$ de CA. A presença de CA é decorrente do processo de fabricação do produto e/ou da degradação do mesmo. Segundo a BRITSH PHARMACOPOEIA [1], são tolerados até $500 \mathrm{mg} / \mathrm{L}$ de CA em soluções comerciais de DGCH $20 \%$.

Tendo em vista que as amostras foram tomadas após o processamento, foi estabelecida a perda de massa decorrente de cada um deles. A cocção em panela de pressão levou a uma redução de $42 \%$, da massa inicial, enquanto a cocção em forno a gás e o processo de fritura resultaram em reduções de $62 \%$ e de $76 \%$, respectivamente. A evaporação da água e solubilização das gorduras devem ser os principais fatores para estas perdas de massa. Esta hipótese deve ser considerada, já que $10 \mathrm{~g}$ da amostra processada seria equivalente a uma quantidade maior da amostra crua, o que pode ser interpretado como um fator de concentração da CA detectada inicialmente.

\subsection{2 - Quantificação em porções definidas de pele tratada e processada em forno de micro- ondas e autoclave}

O processamento térmico de porções definidas de amostra (10g) permitiu a constatação de que o aumento das quantidades de CA ocorreu devido à degradação da DGCH e não somente pela concentração da CA introduzida como contaminante da solução de tratamento (Tabela 3). A comparação dos resultados pode ser feita sem considerar a perda de água e outros componentes durante o aquecimento ou solubilização da CA, tendo em vista que foram analisadas quantidades iguais de uma mesma amostra previamente homogeneizada.

TABELA 3. Resíduos de 4-cloroanilina em amostras de pele tratadas com digluconato de clorhexidina e homogeneizadas ${ }^{1}$ antes do processamento térmico.

\begin{tabular}{lcc}
\hline \multicolumn{1}{c}{ Tipo de processamento } & \multicolumn{2}{c}{ 4-Cloroanilina $(\mathrm{ng} / \mathrm{g})^{2}$} \\
\cline { 2 - 3 } & Média & $\mathrm{CV}(\%)^{3}$ \\
\hline Não processada termicamente & $9 \pm 0$ & 4,6 \\
$\begin{array}{l}\text { Forno de microondas 700W } \\
\text { potência } 50 \% / 10 \mathrm{~min}\end{array}$ & $51 \pm 14$ & 27,2 \\
$\begin{array}{l}\text { Autoclave } 121^{\circ} \mathrm{C} / 1 \\
\text { atmosfera } / 30 \mathrm{~min} .\end{array}$ & $64 \pm 8$ & 11,8 \\
\hline
\end{tabular}

${ }^{1}$ utilizadas alíquotas de $10 \mathrm{~g}$ para o processamento

${ }^{2}$ Análises com 3 repetições

${ }^{3} \mathrm{CV}(\%)$ - Coeficiente de variação \%

A autoclavagem de amostras tratadas com o DGCH levou a um aumento dos niveis residuais de CA em relação à amostra não processada. A diferença entre este resultado e os niveis encontrados após a cocção em panela de pressão pode ser atribuida ao fato de que, durante a autoclavagem, a amostra não ficou diretamente imersa em água e a temperatura atingida na autoclave pode ter sido ligeiramente maior. Estes resultados também estão em concordância com dados publicados por REYNOLDS \& PRASAd [29], indicando a formação de $\mathrm{CA}$ em soluções de clorhexidina 0,01\% autoclavadas a $115^{\circ} \mathrm{C} / 30 \mathrm{~min}$, mas não sob aquecimento a $100^{\circ} \mathrm{C} / 30 \mathrm{~min}$. Apesar disso, deve ser considerado que 
no referido experimento foi utilizado o acetato de clorhexidina em matriz aquosa, que possuem características diferentes do digluconato de clorhexidina e da matriz lipoprotéica empregados no presente estudo.

A Figura 2 mostra que a resposta do detector foi linear para as concentrações de CA avaliadas, podendo esta ser expressa pela equação:

$Y=2,11 \cdot 10^{3} X-2,23 \cdot 10^{4}$

onde: $\mathrm{Y}=$ Área do pico ; $\mathrm{X}=$ Concentração (ng/mL); Coeficiente de correlação $\left(r^{2}\right)=0,999$

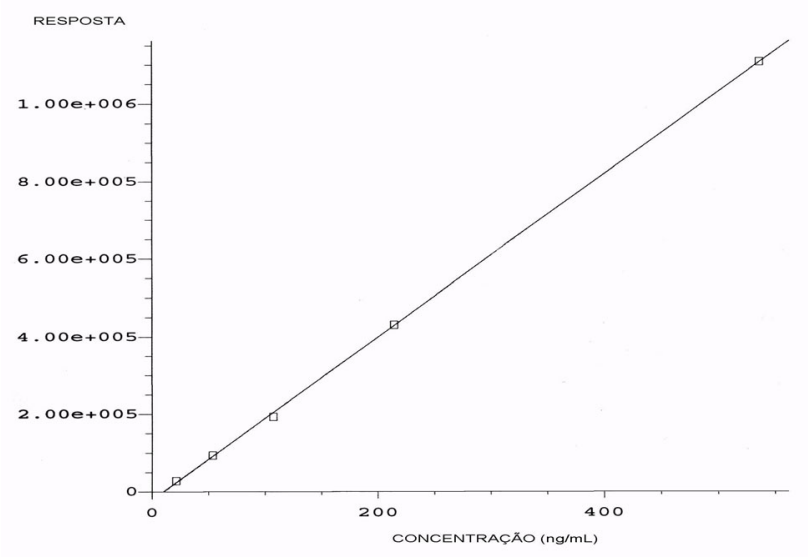

FIGURA 2. Curva padrão de 4-cloroanilina. Diluições em acetonitrila. Análises por CG-EM, coluna HP5-MS, 30m x $0,25 \mathrm{~mm}$ di e filme de $0,25 \mu$, gás de arraste He com fluxo constante de $1,0 \mathrm{~mL} / \mathrm{min}$, com programação de temperatura no injetor e no forno. Espectrômetro de massas operado em modo SIM - 70eV, monitorando os íons $\mathrm{m} / \mathrm{z}$ 127 e 129.

As Figuras 3 e 4 apresentam, respectivamente, os cromatogramas típicos da análise de CA em amostras de pele tratadas com DGCH, antes e após o processamento térmico.

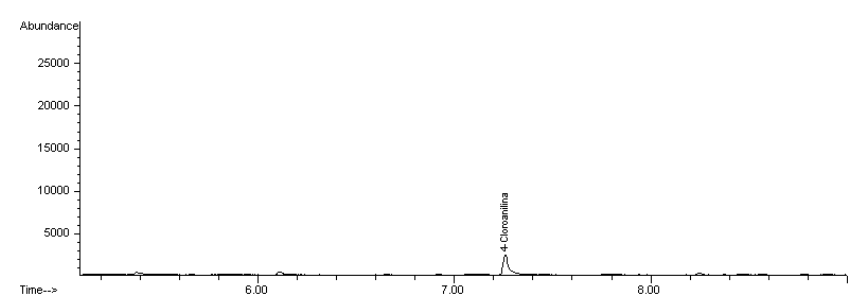

FIGURA 3. Cromatograma típico de 4-cloroanilina $\left(t_{R} 7,26\right.$ min) em pele tratada com digluconato de clorhexidina, não submetida ao processamento térmico. Condições cromatográficas: coluna HP5-MS, $30 \mathrm{~m}$ x $0,25 \mathrm{~mm}$ di e filme de $0,25 \mu$; gás de arraste He com fluxo constante de $1,0 \mathrm{~mL} / \mathrm{min}$; programação de temperatura no injetor e no forno. Espectrômetro de massas operado em modo SIM - 70eV, monitorando os íons m/z 127 e 129. Diluição final da amostra em acetonitrila $10 \mathrm{~g} / 5 \mathrm{~mL}$.

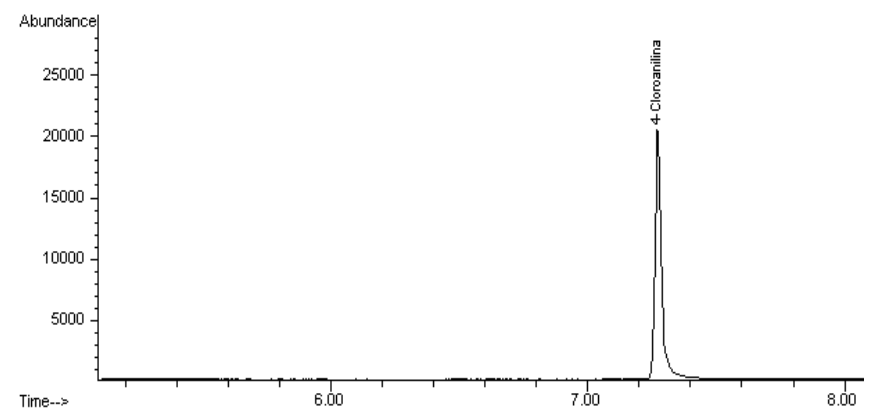

FIGURA 4. Cromatograma típico de 4-cloroanilina $\left(t_{R} 7,26\right.$ min) em pele tratada com digluconato de clorhexidina processada por fritura em óleo de girassol $180^{\circ} \mathrm{C} / 15 \mathrm{~min}$. Condições cromatográficas: coluna HP5-MS, $30 \mathrm{~m} \mathrm{x}$

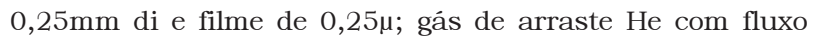
constante de 1,0mL/min; programação de temperatura no injetor e no forno. Espectrômetro de massas operado em modo SIM - 70eV, monitorando os íons m/z $127 \mathrm{e}$ 129. Diluição final da amostra em acetonitrila $10 \mathrm{~g} / 125 \mathrm{~mL}$.

\section{4 - Confirmação de identidade}

A presença dos íns moleculares e a similaridade com os espectros de massas do padrão e da biblioteca NIST98 permitiram a identificação dos picos nos cromatogramas das amostras, cujos tempos de retenção coincidiam com o da CA. Foi confirmada a presença da CA nas amostras tratadas com DGCH antes e após processamento térmico. Nas amostras controle não foram encontrados picos com tempo de retenção equivalentes à CA.

Um cromatograma típico de amostra tratada com DGCH e submetida ao processamento térmico (fritura em óleo de girassol $180^{\circ} \mathrm{C} / 15$ minutos) é apresentado na Figura $5 \mathrm{~A}$. O espectro de massas referente ao pico com tempo de retenção equivalente à $\mathrm{CA}$ e o respectivo espectro da biblioteca NIST98 podem ser observados na Figura 5B.

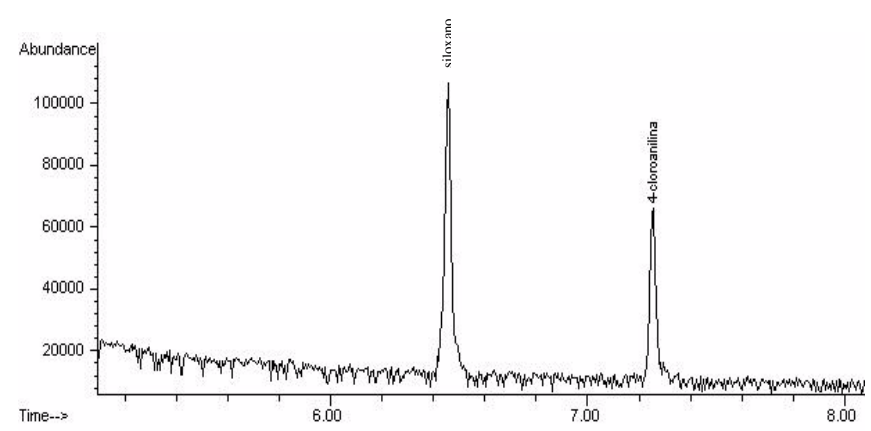

FIGURA 5A. Cromatograma típico de 4-cloroanilina $\left(t_{R} 7,26 \mathrm{~min}\right)$ em pele tratada com digluconato de clorhexidina e processada em óleo de girassol $180^{\circ} \mathrm{C} / 15 \mathrm{~min}$., por CG-EM (SCAN

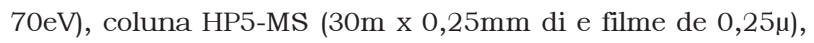
gás de arraste He fluxo constante de 1,0mL/min, com programação de temperatura no injetor e forno. Diluição final da amostra em acetonitrila $10 \mathrm{~g} / 125 \mathrm{~mL}$. No mesmo cromatograma aparece um pico de siloxano liberado da fase estacionária da coluna durante a corrida. 

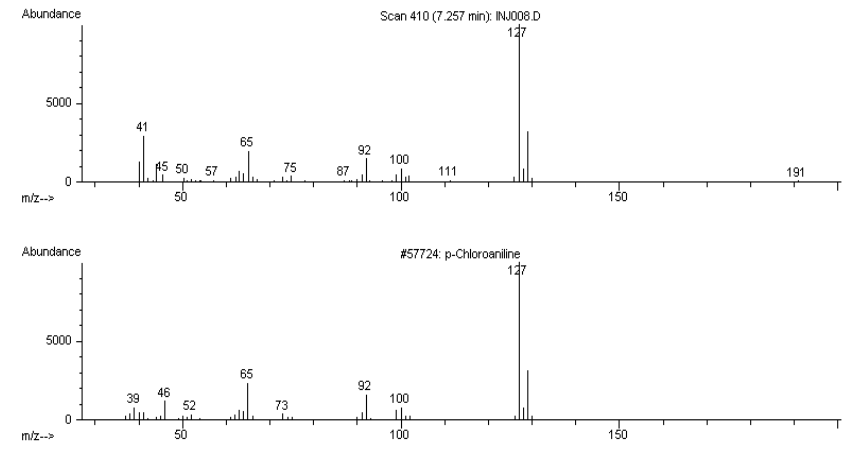

FIGURA 5B. Espectro de massas (modo SCAN $70 \mathrm{eV}$ ) referente ao pico identificado como 4-cloroanilina $\left(t_{R} 7,26 \mathrm{~min}\right)$ do cromatograma de pele tratada com digluconato de clorhexidina e submetido à fritura em óleo de girassol e comparação com espectro da biblioteca NIST98 (inferior).

\section{4 - CONCLUSÕES}

- O método desenvolvido apresentou eficiência, sensibilidade e repetibilidade adequadas para a análise de CA em amostras de pele de frango. O procedimento pode ser considerado robusto, devendo ser tomadas precauções nas etapas de correção de pH do extrato aquoso e evaporação do diclorometano.

- Tendo em vista a presença de residuos de CA em amostras de pele de frango crua após o tratamento com o sanitizante, recomenda-se um controle rigoroso dos niveis deste composto nas soluções de DGCH, caso estas venham a ser utilizadas diretamente nos alimentos.

- O processamento térmico de frangos pode resultar na decomposição do $\mathrm{DGCH}$, formando a CA, ou promover a concentração de resíduos de $\mathrm{CA}$ presentes na amostra crua, possivelmente oriundos da solução utilizada para o tratamento das carcaças.

- Considerando-se o potencial tóxico da CA e a possibilidade de sua presença em frangos após tratamento térmico, recomenda-se que as informações geradas no presente estudo sejam levadas em consideração quando da avaliação da utilização do DGCH como sanitizante de carcaças em abatedouros de aves.

\section{5 - REFERÊNCIAS BIBLIOGRÁFICAS}

[1] BRITISH PHARMACOPOEIA. Office of the British Pharmacopoeia. London: Her Majesty's Stationery Office. v. 1, 398 p., 1993.

[2] BRougham, L.R.; CHENG, H.; PITTMAN, K.A. Sensitive high-performance liquid chromatographic method for the determination of chlorhexidine in human serum and urine. J. Chromatogr., v. 383, p. 365-373, 1986.

[3] CHHABRA, R.S.; THOMPSOM, M.; ELWELL, M.R.; GERKEN, D.R. Toxicity of p-chloroaniline in rats and mice. Food Chem. Toxicol., v. 28, n. 10, p. 717-722, 1990.
[4] CHHABRA, R.S.; HUFF, J.E.; HASEMAN, J.K.; ELWELL, M.R.; PETERS, A.C. Carcinogenicity of p-chloroaniline in rats and mice. Food Chem. Toxicol., v. 29, n. 2, p. 119-24, 1991.

[5] COQUART, V.; HENNION, M.C. Trace-level monitoring of chloroanilines in environmental waters using online trace-enrichment and liquid chromatography with UV and eletrochemical detection. Chromatographia, v. 37, n. 7-8, p. 392-398, 1993.

[6] DAVIES, G.E.; FRANCIS, J.; MARTIN, A.R.; ROSE, F.L.; SWAIN, G. 1:6-di-4'-chlorophenyldiguanidohexane ("Hibitane"). Laboratory investigation of a new antibacterial agent of high potency. British J. Pharmacol., v. 9, p. 192-196, 1954.

[7] DE BALUGERA, Z.G.; GOICOLEA, M.A.; BARRIO, R.J. Determination of 4-chloroaniline and 4-chlorophenyl urea in honey by liquid chromatography with eletrochemical detection. J. Liq. Chromatogr. and Related Technol., v. 20, n. 10, p. 1591-1603, 1997.

[8] DE BRUin, L.S.; JOSEPHY, P.D.; PAWLISZYN, J.B. Solid Phase Microextraction of monocyclic Aromatic Amines from Biological Fluids. Anal. Chem., v. 70, n. 9, p. 1986-1992, 1998.

[9] DI CORCIA, A.; SAMPERI, R. Determination of chloroaniline traces in environmental waters by selective extraction with two traps in tandem and liquid chromatography. Anal. Chem., v. 62, n. 14, p. 1490-1494, 1990.

[10] DJOSAN, D.; FARAJ-ZADAH, M.A. Liquid chromatographic determination of aniline and derivatives in environmental waters at nanoram per litre levels using fluorescamine pre-column derivatization. Chromatographia, v. 41, n. 910, p. 568-572, 1995.

[11] DOI/DIPOA. Autorização de uso de produto (AUP) No 255/99. Brasília, DF, Ministério da Agricultura e do Abastecimento, 1999.

[12] DOUB, W.H.; RUHL, D.D.; HART, B.; MEHELIC, P.R.; REVELLE, L.K. Gradient liquid chromatographic method for the determination of chlorhexidine and its degradation products in bulk material. J. AOAC Int., v. 79, n. 3, p. 636-639, 1996.

[13] FDA. Pesticide Analytical Manual: diflubenzuron (180.377, 186.2000). Washington: Food and Drug Administration - USEPA Headquarters. 12/82, 2000.

[14] FINZI, M.; COSTA, C. Microbiological contamination in food processing plants. Preventive measures. Riv. Soc. Ital. Sci. Aliment., v. 8, n. 4, p. 258-261, 1979.

[15] GAVLICK, W.K. High - performance liquid chromatographic analysis dor chlorhexidine and p-chloroaniline using a specility column and a photodiode-array detector. J. Chromatogr., v. 623, n. 2, p. 375-380, 1992.

[16] GAVLICK,W.K.; DAVIS, P.K. Gas chromatographic determination of p-chloroaniline in a chlorhexidine digluconate-containing alcohol foam surgical scrug product. J. AOAC Int., v. 77, n. 3, p. 583-586, 1994.

[17] GOLLY, I.; HLAVICA, P. The role of hemoglobin in the N-oxidation of 4-chloroaniline. Biochim Biophys. Acta, v. 760, n. 1, p. 69-76, 1983.

[18] HORWITZ, W. Evaluation of analytical methods used for regulation of foods and drugs. Anal. Chem., v. 54, n. 1, p. 67A-74A, 1982.

[19] JAMINET, F.; DELATTRE, L.; DELPORTE, J.P.; MOES, A. Effect of temperature of sterilization and $\mathrm{pH}$ on stability of chlorhexidine in solution. Pharm. Acta Helv., v. 45, p. 60-63, 1970.

[20] KACMAR, P.; PISTL, J.; MIKULA, I. The effect of pchloroaniline on leukocytes of sheep peripheral blood 
under the migration-inhibition test conditions. Immunopharmacol Immunotoxicol v. 17, n. 3, p. 577-584, 1995.

[21] KATAOKA, H. Derivatization reactions for the determination of amines by gas chromatography and their applications in environmental analysis. J. Chromatogr. A., v. 733, p. 19-34, 1996.

[22] KEITH, L.H.; CRUMMETT, W.; DEEGAN Jr., J.; LIBBY, R.A.; TAYLOR, J.K.; WENTLER, G. Principles of environmental analysis. Anal. Chem., v. 55, p. $2210-$ 2218, 1983.

[23] KOHLBECKER, G. Toxic contaminants in chlorhexidine digluconate. Deutsche Zahnarztliche Zeitschrift, v. 44, n. 4, p. 273-276, 1989.

[24] LONG, G.L.; WINEFORDNER, J.D. Limit of detection. A closer look at the IUPAC definition. Anal. Chem., v. 55, 712A-724A, 1983.

[25] MACHADO, R.A. Microbiota bacteriana no processamento industrial de frangos e sua influência na vida útil de carcaças refrigeradas. 1992, 166 p. (Doutorado) Faculdade de Ciências Farmacêuticas/Universidade de São Paulo (USP).

[26] MUlleR, L.; FATTORE, E.; BENFEnATI, E. Determination of aromatic amines by solid Phase Microextraction and gas chromatography-mass spectrometry in water samples. J. Chromatogr. A., v. 791 (1+2), p. 221-230, 1997.

[27] NAGAYAMA, T.; KIKUGAWA, K. Influence of frying and baking on chlorpropham residue. Japan $\mathbf{J}$. Toxicol., v. 38, n. 1, p. 78-83, 1992.

[28] RASMUSSEN, H.T.; OMELCZENKO, N.; FRIEDMAN, S.K.; MCPHERSON, B.P. Determination of chloroanilines in bacterial soaps using cation-exchange chromatography with UV detection. J. Chromatogr A., v. 719, n. 2, p. 434-437, 1996.

[29] REYNOLDS, J.E.F.; PRASAD, A.B. MARTINDALE. The Extra Pharmacopoeia. London: The Pharmaceutical Press. 1982, 555p.
[30] RICHARD, A.; ELBAZ, M.; ANDERMANN, G. Determination of 4-chloroaniline and chlorhexidine digluconate by ion-pair reversed-phase highperformance liquid chromatography. J. Chromatogr. CHROM, v. 16, n. 870, 356-359, 1984.

[31] RODRIGUEZ, E.; DE BALUGERA, Z.G.; GOICOLEA, M.A.; BARRIO, R.J. HPLC/diode-array method for the determination of the pesticide diflubenzuron and its major metabolites 2,6-difluorobenzamide, 4chlorophenylurea, and 4-chloroaniline in forestry matrixes. J. Liq. Chromatogr. Related Technol., v. 21, n. 12, p. 1857-1870, 1998.

[32] SANHUEZA, R.M.V. Efeito do digluconato de clorhexidina e tiabendazólio no controle da podridão causada por Penicillium expansum em maçãs CV. Fuji e Golden Delicious: relatório técnico. EMBRAPACNPFT, Pelotas. 1991, 6p.

[33] TERRA, N.N.; LENZ, G.; GARCIA, S. Avaliação do uso do digluconato de clorhexidina na conservação de carcaças resfriadas de frango: relatório técnico confidencial. Santa Maria: Centro de Ciências Rurais, Universidade Federal de Santa Maria. 1989, 8p.

[34] USEPA - United States Environmental Protection Agency. Reregistration Eligibility Decision - Diflubenzuron. Washington: EPA 738-R-97-008, 1997, 199p.

[35] USEPA - United States Environmental Protection Agency. 1999. Diflubenzuron, tolerances for residues § 180.377 . (As of 4/19/99). "http://www.epa.gov/Fedrgstr/ EPAPEST/ 1999/ April/ Day-19/ 377. pdf”.

[36] Vicente, E.; TOledo, M.C.F. Análise de de digluconato de clorhexidina em frangos tratados antes e após o armazenamento, apresentado no XVII CONGRESSO BRASILEIRO DE CIÊNCIA E TECNOLOGIA DE ALIMENTOS, 8 a 10 de Agosto, FortalezaCE, 2000 .

[37] YOUDEN, W.J. Statistical Methods For Chemists. In: Wernimont, G.T. Use of Statistics to develop and evaluate analytical methods. Arlington: Association of Official Analytical Chemists. 1985, p. 78-86. 